\title{
浅谈唐代书法教育对日本平安时代书法教育的影响
}

\author{
吴帆 \\ 河北美术学院 \\ DOI:10.32629/er.v3i4.2605
}

[摘要] 在日本平安时代, 大批的日本留学生以及僧人来到中国交流学习,书法随之也得到发展, 这些 “遣唐使” 将中国的文字、书法以及书法 教育模式等, 都带回了日本, 于是中国唐代的书法风格、书法教育形式对日本书法的发展产生了非常重要的影响。本文将通过列举中日双方在书 法教育方面的相同点, 阐明中国唐代的书法教育对日本平安时代书法教育的影响。

[关键词] 唐代书法; 教育; 日本

\section{1 唐朝时期中日文化交流概况}

众所周知, 中国书法是日本书法的根源, 而中国的书法家们也以这一 点感到由衰的自豪, 中国书法历史悠久, 值得每一个中国人为之骄傲。要了 解日本书法发展概况, 首先要对日本的历史有大概的了解, 作为分析、判断 和对照的基础。

\begin{tabular}{|l|l|l|l|l|l|l|l|l|l|l|l|}
\hline 古坟 & \multicolumn{2}{|c|}{ 大和 } & 奈良 & \multicolumn{2}{|c|}{ 平安 } & 镰仓 & 室町 & 江户 & 明治 & 大正 & 昭和 \\
\hline 魏晋 & 六朝 & 隋 & 唐 & 五代 & 北宋 & 南宋 & 元 & 明 & \multicolumn{2}{|c|}{ 清 } \\
\hline
\end{tabular}

从上面分期表中我们可以看出, 日本的奈良期约相当于初、盛唐时期, 平安期则历经晚唐、五代、北宋和南宋初期。平安时代, 由于历代天皇对 唐文化的喜爱, 他们在移植汉文化方面不遗余力, 因此书法在这一时期也 得到了较好的发展。

始于贞观四年的八月犬上三田耤, 迄于乾宁元年九月的菅原道真, 日 本在此期间, 向中国派遣 “遣唐使”, 竟达19次之多。使团中除押使、执节 使、大使、判官等官吏外, 还有史生、译语、医师、阴阳师、留学生、学 问僧等各类人物。其中, 留学生和学问僧归国后, 对日本书法的发展产生了 较大的影响。

此外, 值得一提的是, 日本 “遣唐使” 经过学习和考核后, 可以留在中 国做官。例如阿倍仲麻吕汉名昆衡, 大唐开元四年, 作为日本遣唐使来到中 国, 进入长安国子监学习。毕业之后参加大唐的科举考试, 一举考中进士, 步入大唐官场。昆衡最终当上了秘书监兼卫尉卿, 与李白、王维等大诗人 关系极好。那么, 当这些 “遣唐使” 回国后, 中国的政治、经济以及教育制 度, 对日本的影响可想而知。

\section{2 唐朝的书法教育模式对日本书法教育的影响}

2. 1 学校教育

日本自古代社会就有注重书法教育的传统, 并将其保留发展至今。作 为汉字书法的母国, 中国的书法艺术对日本影响深远。书法是文字的表现 形式, 这一特点使书法教育曾经是教育的最基本内容。日本书法教育始于 汉字的引进, 由于汉字进入日本先于教育机构的设立, 因此书法教育的第 一个场所不是学校, 而是宫廷。将历史追溯至奈良时代, 日本参照唐朝国子 监的形式, 在中央设大学, 下设包括书道在内的六道, 是为日本书法教育机 构之始。

在教育制度方面, 唐朝在中央设置两馆和六学的教育机构, 其中的两 馆指弘文馆和崇文馆, 国子监设立国子学、太学、四门学、律学、书学和 算学这六学。公元701年, 日本模仿中国唐朝的国子监制度, 颁布了《大宝 律令》, 由此日本早期教育制度得以确立, 而后参照国子监的形式, 在中央 设大学, 在地方设置国学。国学以各郡司的子弟为教育对象, 在招生人数未
满的情况下可以招收庶民子弟入学。中央设置的大学与地方上的国学相对 应, 其校舍称为 “大学寮”, 因此后世常常将大学叫做 “大学寮”。大学寮 在式部省管辖之下先后设置明经道、算道、音道、书道、纪传道 (文章道)、 明法道六道。与培养律令制国家中下级官吏的大学寮相对应, 又开设了培 养职业技术人员的典药寮、阴阳寮、雅乐寮, 进行医学、药学、针炎、按 摩、阴阳术、天文占卜、历道、雅乐等方面的教育。当时的寮生都寄宿在 学寮内, 于是各氏族纷纷为子弟和族人建立专用的讲堂和宿舍。比较著名 的有菅原氏和大江氏的文章院、和气氏的弘文院、藤原氏的劝学院、橘氏 的学馆院、王氏的奖学院。

在书学教师和教学内容方面, 唐代的《唐六典・卷二十一》载: “书学 博士二人, 从九品下。……书学博士, 掌教文武官八品已下及庶人子之为生 者, 以《石经》、《说文》、《字林》为专业, 余字书亦兼习之。” ${ }^{\circledR}$ 由此可见, 唐代的书学教师由专门的书学博士担任, 而有文献记载的书学博士有孙师 范和裴光远, 他们二人在当时皆以擅长隶书名世。书学生的课程基本有以 下几种: 《孝经》、《论语》、《石经三体书》、《说文》、《字林》、《国语》、《尔 雅》。日本对于书学生的学习内容和教师安排也与唐代类似。日本大学寮 的行政管理机构分 “头”、“助”、“允”、“属” 四个部门, 各道设有专门的 教官, 称为 “博士”, 其中 “书博士” 两名。六道中以明经道为主, 音道和 书道是作为明经道的辅助学科而开设的。明经道约有学生四百人, 主要学 习《周易》、《尚书》、《周礼》、《礼记》、《诗经》、《春秋左氏传》, 还兼修 《孝经》和《论语》。书道的教官称为 “书博士”, 学生叫做 “书学生”。 书博士都有从七位以上的身份位阶, 除教授书道以外, 书博士主要承担明 经道的书法教学任务。据记载, 专门学习书法的 “书学生” 很少, 基本上由 明经道的学生兼修。

在考核方式和出路方面, 唐朝对于书学生的考核分为口试和墨试, 口 试又包括试读和讲义。试读是在所读的经书中每一千言贴二三字, 要学生 试读; 而讲义是在所学习的经书中每二千字贴一条, 要学生讲出其大义; 十条通九条即算通过。口试通过后即可参加墨义考试, 墨义是对《说文》、 《字林》等学习内容, 采用笔试的方法进行考试。表面看来, 唐代的书学考 试似乎没有对书法水平的要求, 但因为有墨义这场笔试, 考官不仅看出学 生掌握字学的程度如何, 同时更可以看出其书写水平的高低。通过明书科 考试的学生, 一般有如下三种出路: 一是胥吏, 如诸台省的令史、书令史等; 二是专门技术人才, 如秘书省、集贤院的楷书手; 三是专业学生, 如装书历 生、天文官生等。由此可见, 明书科出身的人大多是从事书手这样的技术 性职业。

日本对于 “书道” 学生的考核方式也与唐代类似: 由书博士根据书学 生书法水平的高低进行评判并给予成绩。书学生的成绩分为上中下三个档 次, “上第” 和 “中第” 为及第, 即合格, 取得上第的学生将被叙位 “大初 
位上” , 中第授予 “大初位下”。成绩优异的书学生被任以 “内记”一职, 参与起草诏书、诏命等, 同时负责记录天皇的行政和日常活动。此外, 中务 省和图书寮两个部门均设置了 “写书手”一职, 负责经书、史籍等方面的 书写工作, 笔迹秀丽的书学生就被选为 “写书手”。由此可见, 在书学生的 出路方面, 也基本与唐代相同。

\section{2 家学教育}

众所周知, 每个时代都有不同的社会风尚和审美取向, 在唐代, 书法因 唐太宗的推崇, 在社会上蔚然成风, 工书者不胜枚举。宋朱长文在《续书断》 中记载: “书之为教, 古者以参于礼乐, 恶可置哉! 自秦变六体……当彼 之时, 士以不工书为耻, 师授家习, 能者益众。” 。由文献可知, 隋唐时期, 社会上形成了士以不工书为耻的导向, 书法的师授加习等风俗蔚然成风。 日本是以中国的文化母体, 再加上遣唐使的推动和倡导, 这样的社会风气 也对日本产生了较大影响。在日本, 贵族聚会、朝廷际会等场合都需要赋 诗、作和歌并将其书写下来, 因此贵族们以会写汉诗、和歌和精湛的书法 技艺为荣耀; 相反, 如果不具备这样的技能和修养, 则是难登大雅之堂的。

既然有了这样的社会风气, 那么皇室和贵族对于子弟的书法教育必然 会予以重视。他们对于本族子弟的书法教育主要有以下两种方式:

其一, 由善书的父母兄长指导。这样的教育方式在中国的皇室和贵族 当中非常常见, 明代孙承泽在《庚子销夏记》中载: “初, 唐帝王留心学书, 太宗每得二王帖, 轩令诸王临五百遍, 另易一帖, 故所书多可观。” ${ }^{3}$ 由此可 知, 唐太宗对诸皇子的书法教育是非常严格的。日本的皇室和贵族阶层对 于子女的书法教育也同样重视。日本古代的文学巨著《源氏物语》第五回 “紫儿” 中就有源氏公子教导年幼的紫儿苦练书法的场面: “源氏公子写 许多字, 画许多画给她看, 就拿着写给她当作字帖和画帖。……源氏公子对 她说: ‘你也写一张看。”紫儿仰望着源氏公子说: ‘我还写不好呢!' 态度 天真灹漫, 非常可爱。源氏公子不由地满面堆上笑来, 答道: “写不好就不 写, 是不好的。我会教你的。' 她就转向一旁去写了。……那手的姿势和运 笔的方法, 都是孩子气的, 但也非常可爱……的确很幼稚, 但笔致饱满, 显 然前途有望……源氏公子看了, 觉得让她临现世风的字帖, 一定容易进 步。” 源氏指导女儿学习书法并亲自为其书写字帖, 可见父母兄长的指导 也是日本皇室及贵族书法教育的重要形式。

其二, 聘请专门的家庭教师。在唐代, 聘请家庭教师进行书法教育的形 式, 在皇室当中较为常见。《新唐书》卷四十七《百官二》载: “宫教博士
二人, 从九品下。掌教习宫人书、算、众艺。” 由文献可知, 皇室专门聘请 了两位宫教博士, 教授众人书法、算术等众多技艺。日本的皇室和贵族阶 层也是如此, 空海的舅舅阿刀大足就曾担任桓武天皇的皇子伊予亲王的家 庭教师。此外, 皇室也通过聘请以书法为家业的宗家作为教师对其他家 庭成员进行书法方面的指导。对于皇室成员学习书法的要求, 宗家不仅 要由当主进行 “口传”, 还要针对每个字进行细致耐心的指导。尊円亲 王就将自己的老师藤原行房和藤原行尹的 “口传” 写成《入木抄》献给 后光严天皇。

\section{3 结语}

中国与日本有着相似的政治文化背景, 在书法方面又一脉相承, 这使 得中日书法教育的模式构成在一定的历史范畴内存在共性。本文从教育制 度、教学内容、考核方式和学生出路等方面介绍了中日学校教育的相同之 处; 接下来又从家学教育方面入手介绍了中日书法教育的相同点, 这样, 中国书法教育对日本书法教育模式的影响一目了然。这对于我们了解和研 究中日文化交流以及中国文化对日本的影响, 具有一定借鉴意义。

\section{注释：}

(1)(唐)张九龄等.唐六典・卷二十一[M].中华书局,1992:562。

(2)(宋) 朱长文. 《墨池编》卷九《续书断・序》《中国书画全书》(第一册) [M].上 海:上海书画出版社,2009:276.

(3) (明) 孙承泽. 《庚子销夏记》卷六《高宗万年宫铭》 $[M]$. 上海: 上海古籍出版 社,2011.

(4)紫式部著,丰子恺译.源氏物语[M].人民文学出版社,2012:105.

\section{[参考文献]}

[1]向涁.中国古代书法教育研究[M].中国社会科学出版社,2009.

[2]中国教育学会书法教育专业委员会. 日本书法史 [M].天津古籍出版 社,2010.

[3]藤原鹤来.和汉书道史 [M].日本:二玄社,2010.

[4]奥山锦洞.日本书道教育史[M].日本:清教社,1953.

[5]贾佳.日本的书法教育传统[M].东北亚学刊,2016.

\section{作者简介:}

吴帆(1993--),女,汉族,山西大同人,教师,硕士学历,单研究方向: 书法学。 